\title{
IMPROVING THE REACTIVE POWER CAPABILITY OF GRID CONNECTED DOUBLY FED INDUCTION GENERATOR
}

\author{
N. O. Ogbogu \\ Electrical/Electronic Engineering Department \\ University of Port Harcourt, Rivers State, Nigeria \\ Adebayo Adeniyi D. \\ Electrical/Electronic Engineering Department \\ Federal University, Otuoke, Bayelsa State, Nigeria
}

\begin{abstract}
Due to increasing wind power generation in the electric power system, the reactive power generation by the wind farms is a major concern during both steady state and faulty conditions. This work, first, presents the reactive power capability (RPC) curve of doubly-fed induction generator (DFIG) considering three limitations (rotor voltage, rotor current and stator current) for reactive power production/consumption, for the complete operating range which is obtained by optimal rotor speed employing maximum power point tracking (MPPT) algorithm. It is established that the total reactive power generation is limited by rotor voltage at low speeds and by rotor current at higher speed. However, the total reactive power consumption is limited by stator current, for entire operating region. Selection of partial rated converter rating is crucial in terms of cost, efficiency, operating speed range and reactive power capability. The effect of converters rating on the enhancement of RPC of doubly fed induction generation is analyzed. Complete capability curves of DFIG for different stator voltages are developed considering grid-side converter (GSC) contribution towards reactive power capability.
\end{abstract}

Keywords: Reactive Power, Power System, Doubly Fed Induction Generator, Power factor, Grid side Converters and Reactive Power Capability

Cite this Article: N. O. Ogbogu and Adebayo Adeniyi D, Improving the Reactive Power Capability of Grid Connected Doubly Fed Induction Generator, International Journal of Electronics and Communication Engineering and Technology, 10(5), 2019, pp. 9-22.

http://iaeme.com/Home/issue/IJECET?Volume=10\&Issue $=5$ 


\section{INTRODUCTION}

The fluctuating global fuel prices, concerns with the depleting fossil fuel reserves and apprehension relating to climate change has resulted in an increasing focus on renewable sources to satisfy rising global energy requirements. Amongst the available renewable sources of energy wind and hydro are the most feasible for utility scale power generation (Miller, 2010). With a majority of the hydro reserves around the world reaching the maximum capacity in terms of available power there is an increasing shift towards wind power generation to satisfy the need of a clean renewable source. The year 2008 was a record year for wind generation in the United States with a total increase of $8,360 \mathrm{MW}$ which is $50 \%$ of the total wind capacity at the end of 2007 . Wind energy accounted for $42 \%$ of the total new capacity added. In 2008 , the United States overtook Germany to become the country with the largest installed wind power capacity in the world. The total wind power capacity of the United States is at 25,170 MW. Federal policy in the form of production tax credits and state regulations in the form of renewable portfolio standards (RPS) have contributed to encouraging the development of wind generation in the United States. Over 25 states have accepted RPS by requiring a substantial contribution from renewable sources of energy to their power generation portfolio.

\subsection{Importance}

This work will bring to light the relevance the positive impact that utilizing the capability curve of wind parks has on the voltage performance of a power system. The additional benefit is especially amplified for those wind parks that are in close proximity to load centers. It will introduce an opening in to the use of Wind power, which has been proved to be a potential source for generation of electricity with minimal environmental impact is the fastest-growing source for electric power generation, and it is expected to remain so in the future. It will also serve as reference material for future research on improving the reactive power capability of grid connected doubly fed induction generator.

\section{DOUBLY-FED INDUCTION GENERATORS}

The Doubly Fed Induction Machine is shown in figure 1. It consists of a wind turbine that is connected via a gear train to the rotor shaft of the induction generator. The rotor terminals of the induction machine are connected to the four-quadrant power electronic converter capable of both supplying real/reactive power from the grid to the rotor as well as supplying power from the rotor to the grid. The converter consists of two separate devices with different functions, the generator side converter and the grid side converter. The generator side converter controls the real and reactive power output of the machine and the grid side converter maintains the DC link voltage at its set point. These converters are controlled respectively by the Generator side controller and the Grid side controller. The DFIG also has a wind turbine control that maximizes the power output from the turbine via pitch control and sends this computed maximum power output Pgrid, to the converter. The Power electronic converter is connected to the grid via a transformer that steps up the voltage to the grid. The stator side of the induction generator is also connected to the grid via a step up transformer. The point of interconnection with the grid is the point used to measure the active and reactive power output of the wind farm. In case the system reliability requires that additional reactive power be injected a STATCOM may be connected at this point of interconnection. 


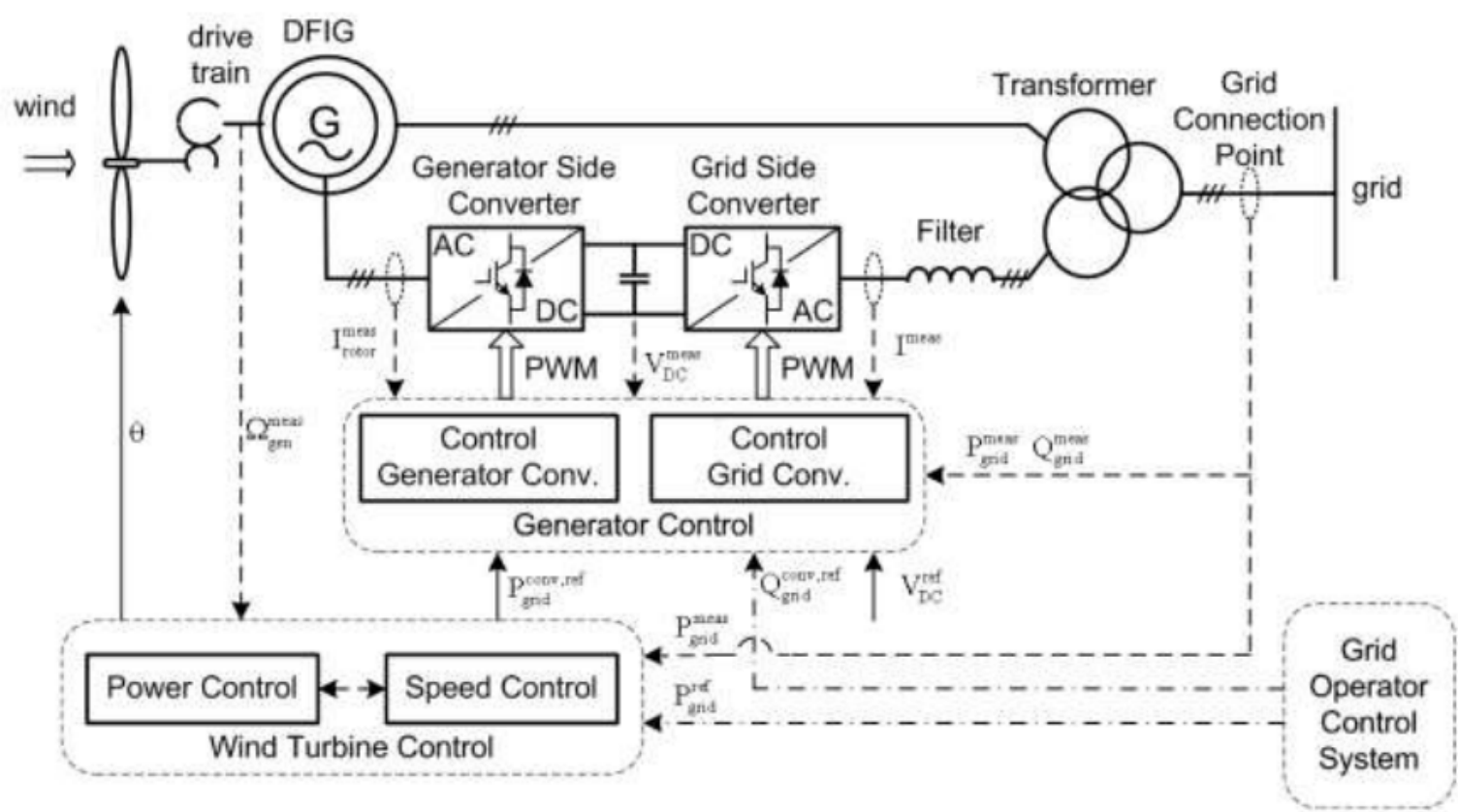

Figure 1 Schematic of a Doubly Fed Induction Generator

The doubly fed Induction generator consists of a three phase induction generator with three phase windings on the rotor. The rotor is connected to a converter which supplies power to the rotor via the slip rings. The power electronic converter is capable of handling power flow in both directions which permits the DFIG to operate at both sub synchronous and super synchronous speeds. The DFIG produces controlled voltage $V 1$ at grid frequency $f 1$ at the stator and variable voltage $V 2$ is provided at the rotor at variable frequency $f 2$. The frequency of the rotor depends on the angular velocity of the rotor which in turn depends on the wind speed. Let $f r$ be the electrical frequency of revolution of the rotor. The following relation holds between the various frequencies:

$$
f_{r}=f_{1} \pm f_{2}
$$

The positive sign above is for the super synchronous operation where rotor speed exceeds rated speed and negative sign is for sub synchronous operation when rotor speed is less than rated speed. At super synchronous speed the phase sequence of the rotor currents is the same as the stator and power is supplied from the rotor to the grid. In the sub synchronous operation power is drawn by the rotor from the grid and the phase sequence of rotor currents is opposite to the phase sequence of the stator currents. The steady state operation of the DFIG is only restricted by the converter ratings of the rotor side converter. The maximum power rating of the rotor side converter ( ) is generally $25 \%-30 \%$ of the Induction machine ratings. Thus if the converter is operated such that all magnetizing power is provided by the stator, the maximum rotor power supplied/absorbed is Pmax, and the maximum magnitude of slip for operation is given by

$$
s_{\max }=P_{\max } / P_{\text {rated }}
$$


Where, Prated is the rated power output of the DFIG. This means that the DFIG can provide an operating range of $75 \%$ to $125 \%$ of the rated wind speed. Also the pitch control with maximum power tracking allows the DFIG to produce maximum power at different wind speeds thus increasing overall efficiency of the unit.

The space phasor equivalent circuit of a DFIG is given below:

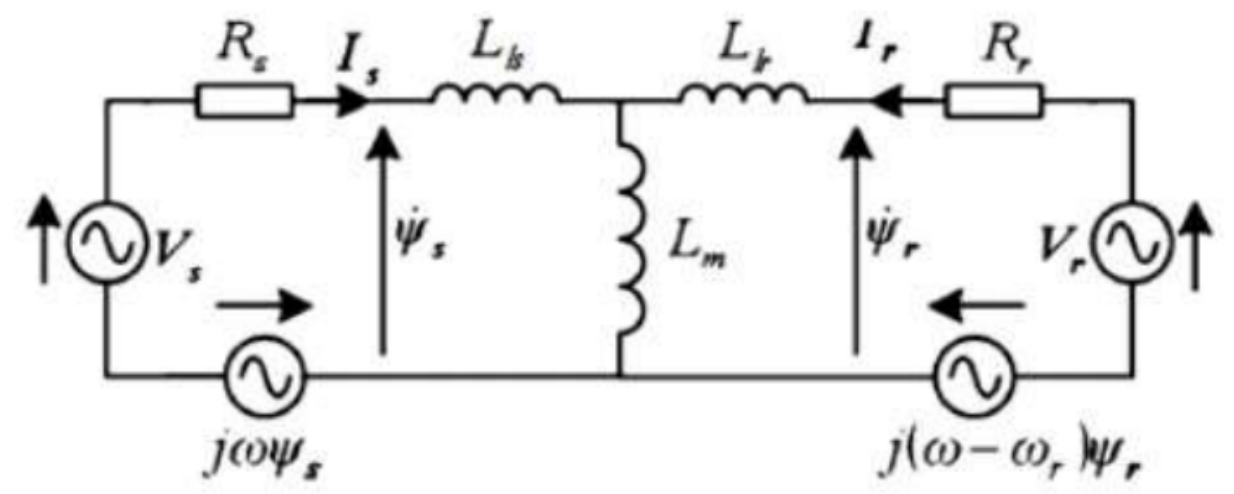

Figure 2 Space Phasor Equivalent Circuit

Considering a synchronously rotating reference frame with $\omega=\omega 1$, and converting to time domain, the following equations are obtained:

$$
\begin{aligned}
& I_{s} R_{s}+V_{s}=-\frac{d}{d t} \Psi_{s}-j \omega \Psi_{s} \\
& I_{r} R_{r}+V_{r}=-\frac{d}{d t} \Psi_{r}-j\left(\omega-\omega_{r}\right) \Psi_{r}
\end{aligned}
$$

\subsection{Control of Generator Side Converter}

Now the stator flux is more or less constant and thus is assumed to be a constant. It is also assumed that saturation does not occur. Also stator resistance is negligible and hence the stator resistance is assumed to be zero. Now we select the $\mathrm{d}-\mathrm{q}$ axis such that the stator flux $\Psi_{S}$ is along the d axis. Therefore $\Psi q=0$. Also since we assume that $\Psi d$ is constant $d d t \Psi d=0$. Now using these values in the stator equation of (3) we obtain:

$$
\begin{aligned}
& V_{d}=0 \\
& V_{q}=-\omega_{1} \Psi_{d}
\end{aligned}
$$

Now, rearranging the stator flux equation to obtain Is in terms of the other values:

$$
I_{s}=\Psi_{s}-\frac{L_{m}}{L_{s}} I_{r}
$$

Where $L s=L s l+L m$ Now power delivered at stator is given by:

$$
S s=V S * I S
$$


Thus, $P s=32(V d I d+)=32$

Vq Iq $=32 \omega 1 \Psi d$ Lm Ls Iqr

$$
Q_{s}=\frac{3}{2}\left(V_{d} I_{q}-V_{q} I_{d}\right)=-\frac{3}{2} V_{q} I_{d}=\frac{3}{2} \omega_{1} \Psi_{d}\left(\Psi_{d}-\frac{L_{m}}{L_{s}} I_{d r}\right)
$$

From the above equation it is observed that $P s$ can be controlled by the Iqr component and the $Q s$ component can be controlled by the $I d r$ component, assuming the stator flux is constant. Thus the appropriate control can be applied to the rotor side converter to obtain the required $I d r$ and $I q r$ for the set point $P s$ and $Q s$ values. This is the decoupled control of the active and reactive power in a DFIG.

\subsection{Impact of Doubly Fed Induction Generator Capability Curve on Steady State Operation}

Reactive Power Requirements in a Power System a majority of the newly installed wind generation consists of doubly fed induction generators (DFIG). As more units start coming online, increasing levels of wind penetration has generated a widespread concern over its impact on power system performance. There are primarily two reasons for such a concern, the variability of wind and the nature of the generator which is different from conventional units. The effect of high wind penetration levels on system performance becomes critical in the planning of future units and to accomplish the requirements of the various states RPS. The precise modeling of DFIG units is important for both static and dynamic analysis of power system performance. To accurately assess the stability of a system and to prevent voltage violations, computation of available reactive power in the system is essential.

\subsection{Reactive Capability Limitations}

The reactive power capability of any generation unit on the power system is essential in studying long term stability and voltage stability. Traditional synchronous generators have limitations in terms of maximum current and heating of the machine. The active power of the machine is limited by the prime mover capability. The reactive current output capability is dependent on the armature current limit, field current limit and heating limit of the coils. The armature current limit is the maximum temperature limit on the stator winding coils. Similarly, the field current limit is the maximum temperature limit on the field coil. Thus, the reactive capability of the synchronous generator depends on the machine limitations. A Doubly Fed Induction Generator (DFIG) has advantages over the Singly Fed Induction Generator in its inherent capability to handle variable wind speed. The rotor side converter injects currents and voltages according to various wind speeds. The following figure indicates the variation in power output of a DFIG with respect to the wind velocity. It also indicates the variation in rotor slip with wind speed. This figure can be used to determine the rotor slip at different power output levels.

\section{METHODOLOGY}

Wind generation cannot be considered to be dispatch able and hence a different approach is needed to understand the impact of wind variability on Voltage Stability Margin. With increasing environmental concerns and political mandates, wind energy is becoming the preferred choice of renewable energy. Wind energy dispatch will play a pivotal role in order to meet the renewable portfolio standard to make wind generation comprise $20 \%$ of the whole power generation portfolio in the US by 2030 . Electricity generated from wind power can be highly variable with several different timescales - hourly, daily, and seasonal periods are present in wind energy. Since instantaneous electrical generation and consumption must remain in 
balance to maintain grid stability, this variability can present substantial challenges to incorporating large amounts of wind power into a grid system.

Figure 3 below demonstrates a sample VSROp. The four PV curves corresponds to no wind and wind generations W1, W2 and W3 (W3 $>$ W2 $>$ W1). For each PV curve the amount of wind generation is kept constant and the load and generation is increased according to a set loading and generation increase scenario, which is kept constant for all PV curves. Another input to the PV surface calculation algorithm is the redispatch strategy for increase or decrease in wind generation.

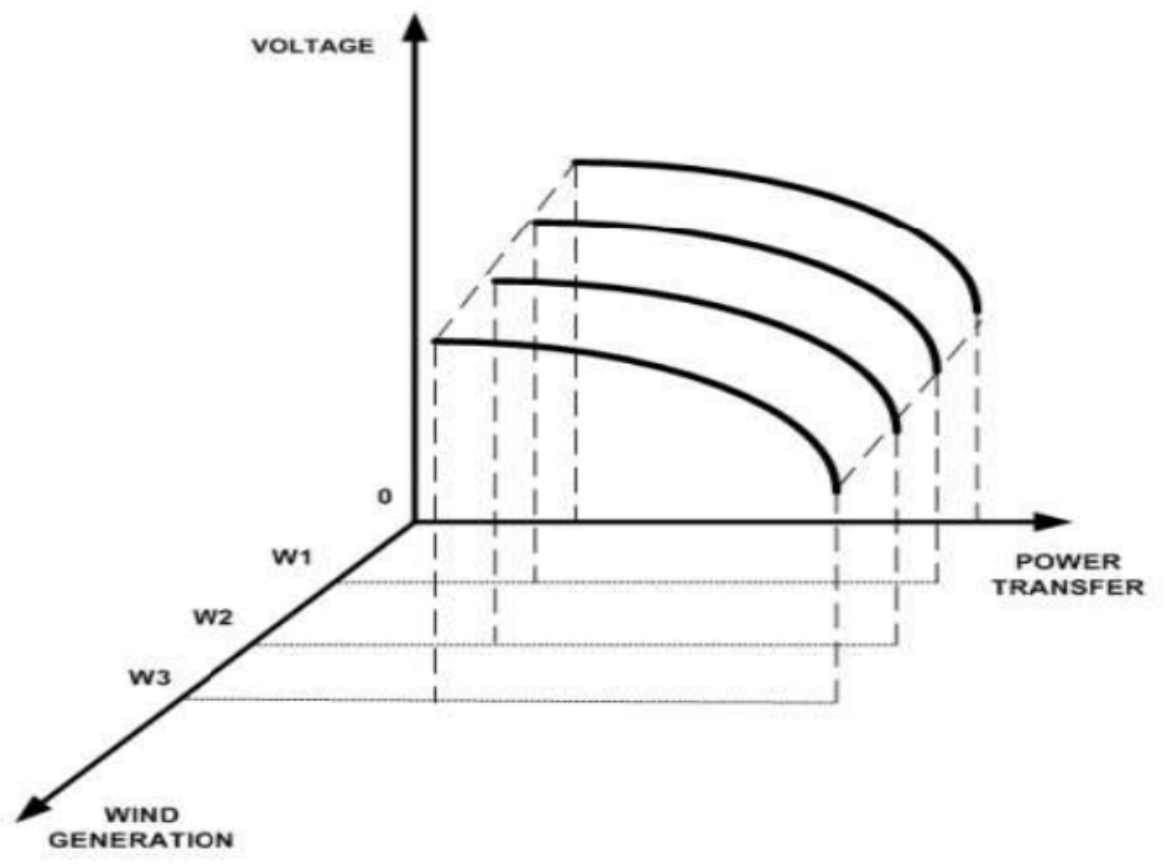

Figure 3 Voltage Secure Region of Operation (VSROp)

The flowchart for the proposed methodology is shown in Figure 3. The proposed methodology includes the following steps:

\section{Step 1: Obtain Input Data}

This step basically involves obtaining the three inputs to the Voltage Security Assessment tool: The power flow data for the system under consideration, the assumed level of wind generation in the base case and wind variability that is to be studied. The re-dispatch strategy for increase or decrease in wind generation. The power flow data includes the committed generations and their bid curves. It also includes the load increase direction and generation increase direction. The generation increase scenario is provided for all other generations except wind. Historical wind speed data and load data is utilized to decide the amount of wind generation available in base case. The wind speed forecasts for maximum variability is utilized to decide at what values of wind variation PV curves are to be plotted. The wind speed rate of variation along with the ramp rates of available generation is utilized to develop the generation re-dispatch strategy to compensate for variation in wind power in the system.

\section{Step 2: Optimal Power Flow in the base case}

Optimal power flow (OPF) methodology developed is utilized. MATPOWER is the software tool used to conduct the OPF analysis. 


\section{Step 3: Full Contingency based Margin}

Estimation For a fixed wind energy dispatch, plot the PV curves using power flow for all (n1) contingencies. MATPOWER is used to obtain the PV curves. The contingency corresponding to the least power transfer margin is noted and the corresponding PV plot is stored. The set of all PV curves is plotted in the previously mentioned three dimensional space to obtain the Voltage secure PV surface. The series of PV curves on different planes corresponding to a particular wind penetration level will constitute a hyperspace which will represent the stable voltage operating zone The base case dispatch is then utilized to estimate the least available margin in the PV surface.

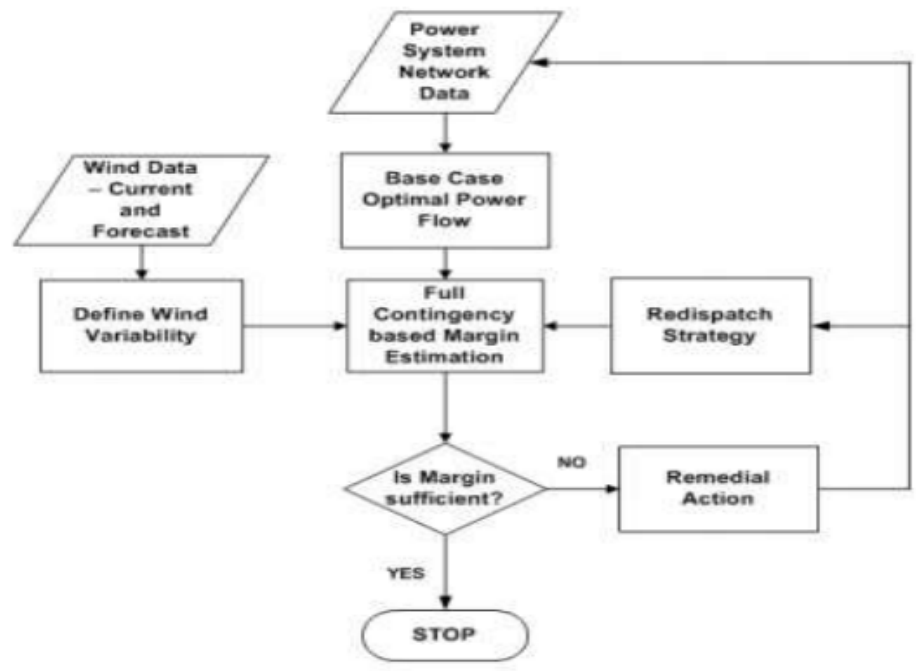

Figure 4 Flowchart for Voltage Security Assessment

\section{Step 4: Margin Check and Remedial Action}

The margin obtained in Step 3 is verified to meet the power margin requirements. If the margin requirements are not met then remedial actions are taken to increase the margin and the modified load flow data is fed into step 1 and the entire process is iteratively repeated until the desired margin is obtained. The remedial actions that can be taken include but are not restricted to capacitor switching, commitment of additional generation units or load shedding. This hyperspace would give the power system operators a given region which might be too conservative, but is the perfectly safe operating zone. Also given current wind dispatch and estimated variability in the next hour, the operator would be able to quickly determine the amount of the margin that would be available for the system.

\subsection{Dynamic Simulation Setup}

This section examines the impact of the additional reactive capability on dynamic voltage performance. The same three cases utilized are utilized in this section as well. The following sections describe the different components that are modeled in the dynamic simulation. The purpose of this analysis is to verify the results obtained in the steady state analysis described

\subsection{Generator Modeling}

The dynamic model for the above system is obtained from the Eastern Interconnection dynamic model. The dynamic simulation is carried out in PSS/E. The 57 online units have dynamic models. The generator model used is the round rotor generator model (GENROU). The following table 1 indicates the different exciters used in the dynamics data. 
Table 1 Different Exciter Models Used in the System

\begin{tabular}{|c|l|}
\hline Exciter Code & \multicolumn{1}{|c|}{ Description } \\
\hline ESAC1A & 1992 IEEE type AC1 A excitation system model. \\
\hline ESAC8B & Basler DECS model. \\
\hline ESAC3A & 1992 IEEE type AC3A excitation system model. \\
\hline ESST1A & 1992 IEEE type ST1A excitation system model. \\
\hline EXAC2 & 1981 IEEE type AC2 excitation system model. \\
\hline EXST1 & 1981 IEEE type ST1 excitation system model. \\
\hline IEEEX1 & 1979 IEEE type 1 excitation system \\
\hline ESST3A & 1992 IEEE type ST3A excitation system model. \\
\hline EXPIC1 & Proportional/integral excitation system model. \\
\hline
\end{tabular}

The different governor models used in the system are given below in table 8 . The PSS2A type stabilizer is also used for some generators. The PSS2A is the IEEE Dual-Input Stabilizer model.

Table 2 Different Governor Models Used in the System

\begin{tabular}{|c|l|}
\hline Governor Code & \multicolumn{1}{|c|}{ Description } \\
\hline GGOV1 & GE general purpose turbine-governor model. \\
\hline IEEEG1 & 1981 IEEE type 1 turbine-governor model. \\
\hline WESGOV & Westinghouse digital governor for gas turbine. \\
\hline IEESGO & 1973 IEEE standard turbine-governor model. \\
\hline TGOV1 & Steam turbine-governor model. \\
\hline
\end{tabular}

\subsection{Tap-Changer Modeling}

Online tap changers are devices used to adjust the taps of a transformer. The taps of a transformer help change the ratio of the primary to the secondary winding of the transformer. The primary application of tap changers is to boost up the voltage on the lower $\mathrm{kV}$ side of the transformer to maintain load voltages. The tap changers are dangerous in a system that is close to voltage instability. Whenever transformer taps are adjusted the reactive power absorbed or injected into the grid on the high $\mathrm{kV}$ side of the transformer changes. When the taps are adjusted to increase the voltage on the low $\mathrm{kV}$ side, additional reactive power is absorbed from the grid. 
Table 3 Components of Wind Turbine Model

\begin{tabular}{|l|l|}
\hline Model Code & Description \\
\hline GEWTG1 & Wind Turbine Generator \\
\hline GEWTE1 & Wind Turbine Electrical Control \\
\hline GEWTT & Two Mass Shaft Model \\
\hline GEWTA & Wind Turbine Aerodynamics \\
\hline GEWTP & Pitch controller \\
\hline WGUSTC & Wind Gust Model \\
\hline
\end{tabular}

The regulated voltage is set to 1.04 . The other models are the standard pitch control model (GEWTP) and the aerodynamic model (GEWTA) that handles the mechanical power input from the blades. The two mass shaft model (GEWTT) consists of the generator inertia and the inertia of the blades. The wind gust model (WGUSTC) is used to simulate wind gusts and ramps. Since we are looking at a small time frame $(<5 \mathrm{~min})$, the wind speed is assumed to be constant throughout the simulation.

Interconnection bus is used as the remote bus to be regulated. The regulated voltage is set to 1.04. The other models are the standard pitch control model (GEWTP) and the aerodynamic model (GEWTA) that handles the mechanical power input from the blades. The two mass shaft model (GEWTT) consists of the generator inertia and the inertia of the blades. The wind gust model (WGUSTC) is used to simulate wind gusts and ramps. Since we are looking at a small time frame $(<5 \mathrm{~min})$, the wind speed is assumed to be constant throughout the simulation. 


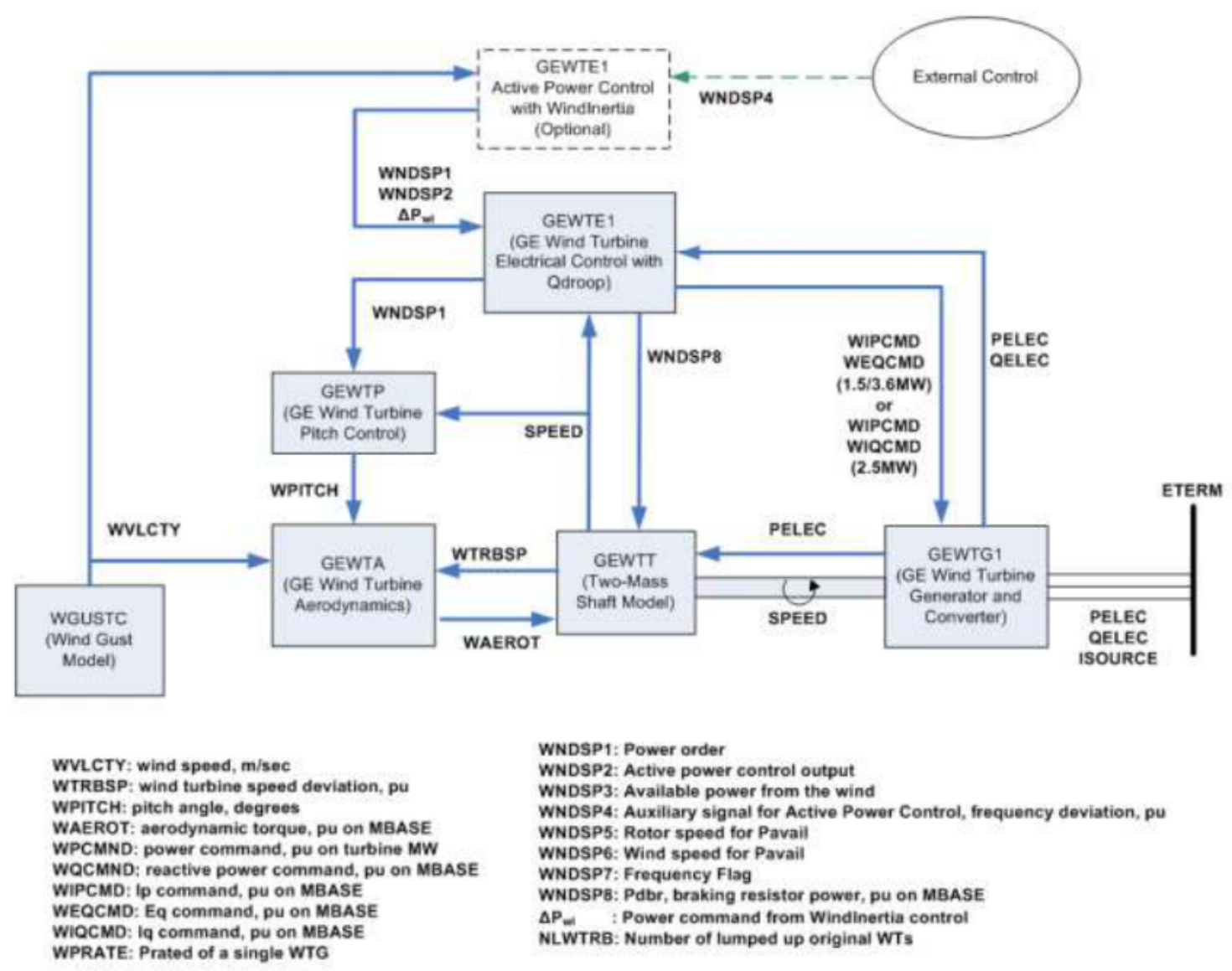

Figure 5 Schematic Diagram

\section{ANALYSIS AND DISCUSION OF FINDINGS}

\subsection{Simulation Results}

The dynamic analysis is done to verify the results obtained from the static voltage stability analysis. To simulate the effect of Under Load Tap Changers (ULTC's), the model is included. The load is modeled as a constant MVA load for the static analysis. The dynamic simulation software's like PSS/E do not allow for constant MVA load model. The load has to be converted to either a constant current model or constant impedance model. The constant impedance model is the least conservative model. The real power load is converted to a constant current load and the reactive load is converted to a constant impedance load. This assumes an intermediate assumption for load behavior and proximity to voltage collapse. The same cases are used for the dynamic analysis as the steady state analysis.

\subsection{Wind Plant at $100 \%$}

The maximum load obtained with the static analysis in section 4.3 is $770 \mathrm{MW}$ with the wind farm at maximum output. Thus, the initial load zone load is set to $775 \mathrm{MW}$. The following plots indicate the voltages at the three monitored buses and the reactive power output from the two wind parks. 


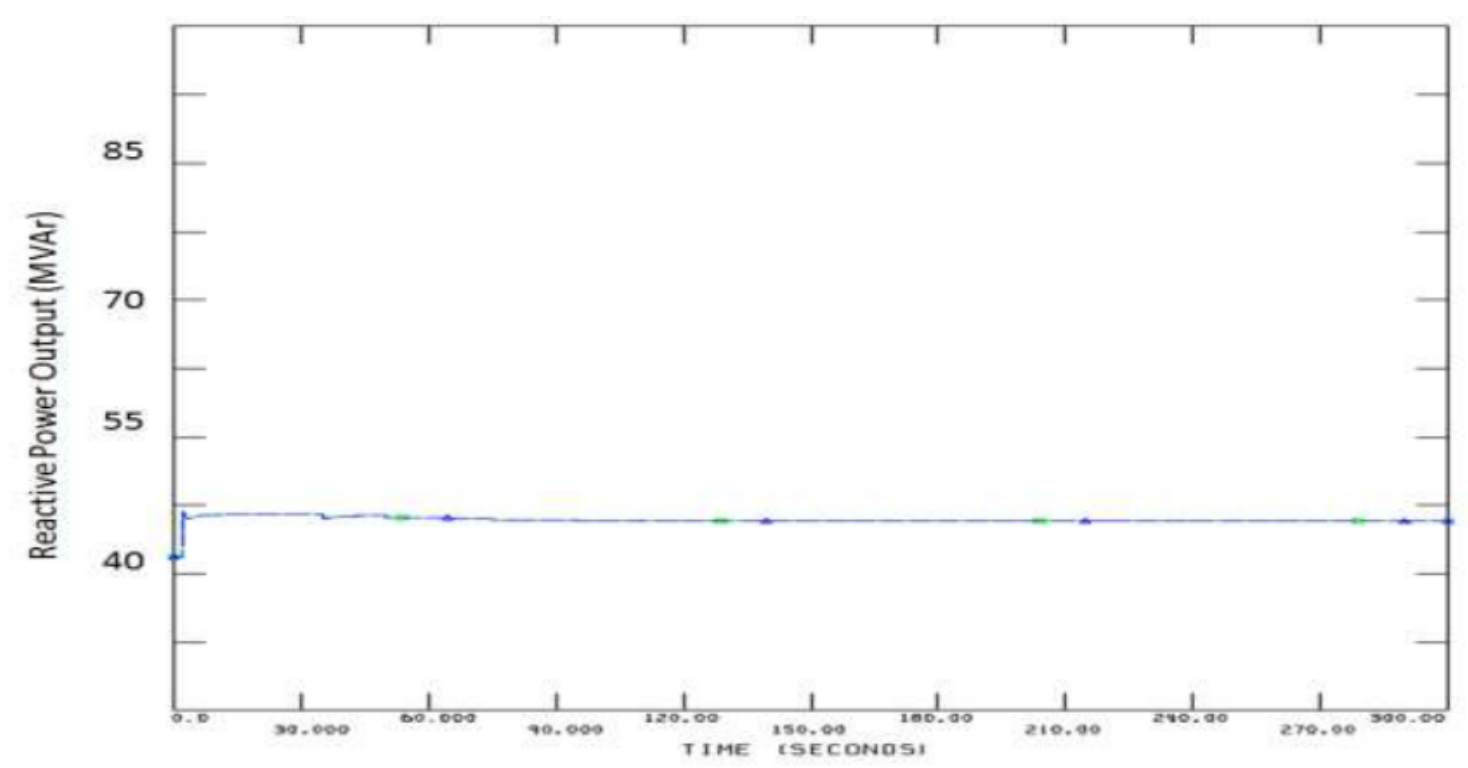

Figure 6: 300 Second Reactive Power - Load = 775 MW Wind 100\%

The next load level that is tested is $800 \mathrm{MW}$. At this load level, the pre contingency voltage at WF1 violates the criteria. But from figures 5-6 it is evident that the post disturbance voltages are over 0.9 p.u and there is no criteria violation.

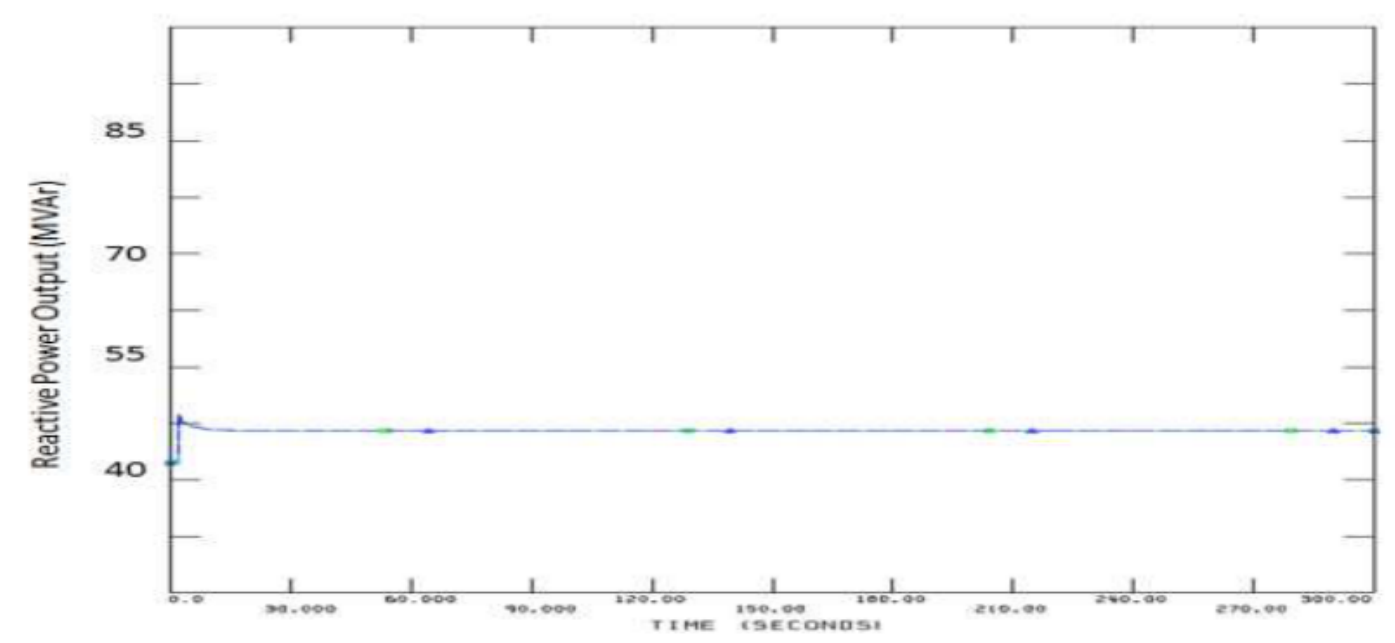

Figure 7: 300 Second Reactive Power - Load $=800$ MW Wind 100\%

The figure 6 shows the reactive power outputs of the two parks. The wind parks in this case hit their reactive limit, but it remains flat at that level, which indicates the minimal tap changing events. The load is increased further until there is post contingency voltage violation. At 850 MW, the post contingency voltage just after the disturbance reduces below 0.9 p.u. Figure 7 shows the voltage reduces below the minimum value of 0.9 .

\subsection{Wind Park $5 \%$ - Providing Reactive Power}

The final case is the case with $5 \%$ wind providing reactive power support to the load pocket. The first load level tested is $825 \mathrm{MW}$. This load is just beyond the maximum secure load that can be served in this scenario. At this load level, the voltage at WF1 for the pre-contingency 
case is just below 0.95 p.u as seen in figure 6 . The reactive power output from the parks as seen in figure 7, increases with time but is still below the maximum value of 96 MVAr.

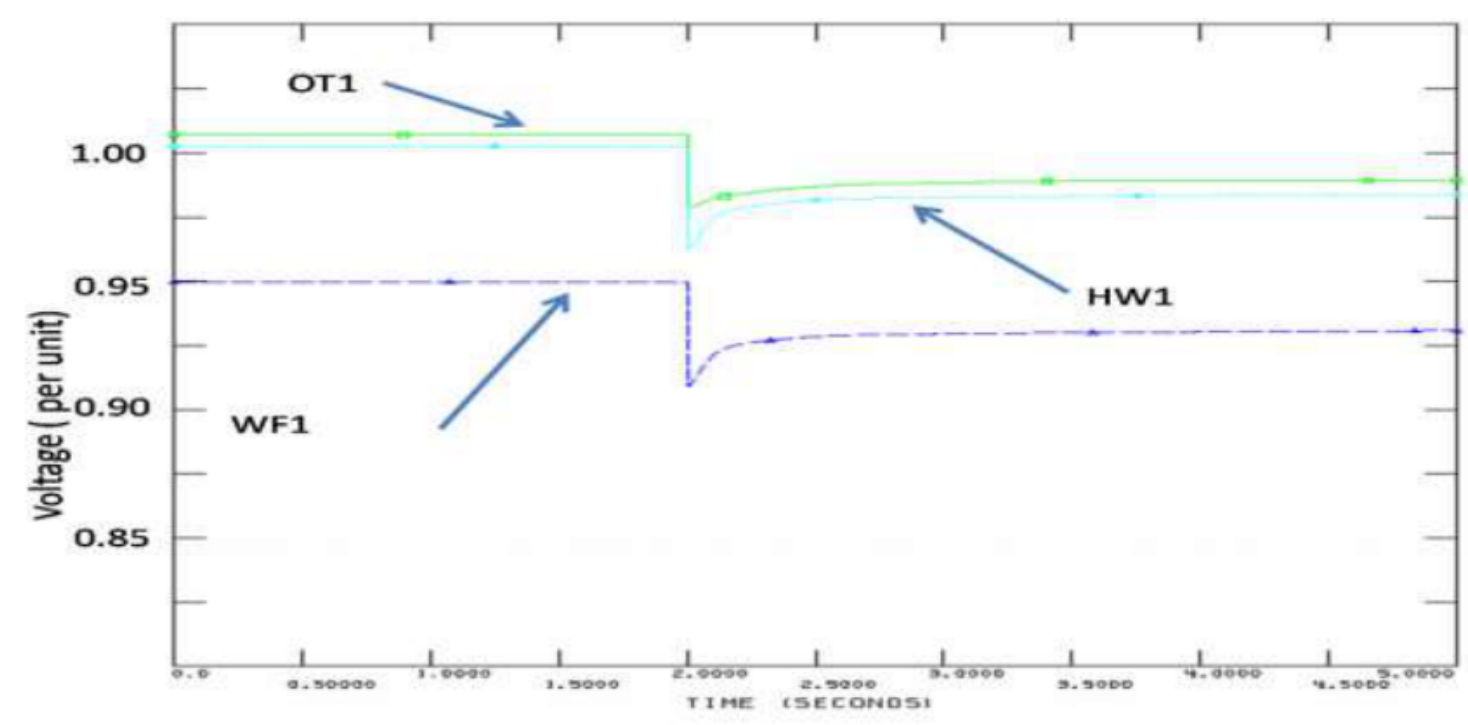

Figure 8: Second Voltage Profile - Load $=825 \mathrm{MW}$ Wind $-5 \%$

\section{DISCUSSION OF FINDINGS}

This section demonstrates the benefit of utilizing the capability curve of an off shore wind park to reliably serve load during low wind periods. The proximity of off shore wind farms to load centers and the reactive power requirements of load pockets makes it favorable to utilize the reactive capability to prevent voltage issues in the load center. The periods of low wind correspond with periods of high load. High load time periods are times when the system reactive reserves are at their lowest.

The accessibility of wind farms as a reactive power source will lead to higher import capabilities into the coastal load pockets from remote generation. In essence the additional reactive capability helps the power system handle the unavailability of wind. Both steady state and dynamic simulations demonstrate the improved transfer capability into the load pocket. The effect of online tap changers on the post disturbance voltages was also studied. The results in this section make a strong case for off shore wind generation and the ability to handle wind variability more effectively by utilizing the full reactive capability of a DFIG wind park.

\section{CONCLUSION AND RECOMMENDATIONS}

The DFIG machine in voltage control mode has significant reactive power capability, which can contribute to improved system performance. The FERC mandated requirement of maintaining power factor at the interconnection restricts the wind park from maximizing its contribution to improved voltage performance. DFIG wind parks implementing capability curve control may substantially reduce system losses, especially at low plant output levels. The additional reactive capability leads to larger power transfer capability in the system

In this work, a novel voltage stability assessment tool that incorporates wind variability is developed. The technique developed is general and is applicable for any type of wind generation technology. The traditional methodology of drawing PV curves to assess static voltage stability margin is modified to address the intermittent nature of wind energy. Given a range of wind variability, the developed tool calculates sets of PV curves plotted along parallel planes, thus giving a three-dimensional VSROp. The tool is used to determine the VSROp for a 23-bus test 
system. It is then utilized to compare the effect of utilizing the DFIG capability curve over the FERC mandated \pm 0.95 power factor requirement. The results demonstrate that restricted power factor operation could lead to an overly conservative estimate of the power transfer capability of the system, while use of the capability curve causes a substantial increase in the power transfer capability of the system. Also, the results demonstrate that the redispatch. Large scale penetration of wind energy in the system raises significant concerns regarding the reliability implications of large scale variable generation.

The work presented in this work provides a methodology to utilize the capability curve of the DFIG machine to enhance the voltage performance of the system. By utilizing wind parks as reactive sources during low wind periods can facilitate maintaining balanced system voltages. Not all wind parks will provide a significant impact, but any wind park that has direct access to load centers or is on a transmission path carrying large amounts of power; will provide a substantial system performance improvement. Since the general trend for on shore wind is having low wind centers closer to load and high wind regions away from load, the wind parks closer to the load centers can facilitate more power from the remote high wind areas to access the load pockets. This allows for maximum utilization of the transmission system built for large scale wind integration. An example for this can be seen by considering a wind park close to the load center. During periods of high wind at the wind park closer to load, it will provide real power to the load center. When the wind park close to the load has low wind levels, it will provide reactive power which will facilitate maximum transfer of power from the distant wind generation.

Since the general trend is that remote wind parks have better capacity factors, there is a high probability that when the wind park close to the load is having low power outputs, the remote wind park will tend to have better wind levels. In the case of off shore wind parks, their proximity to load pockets makes the ability to provide reactive power to the load pockets a significant benefit in terms of reliability improvement.

Finally, the VSROp methodology is a general method to analyze systems with large scale wind penetration and determine the susceptibility of the system reliability to wind variability. The methodology helps assess if a particular dispatch strategy will adversely impact the system reliability, if the wind ramps up or down. The work demonstrates that the critical contingency and the transfer margin vary with the wind levels on the system. Also the variation in transfer margin is not monotonic, and the system topology and generator levels will impact the variation in transfer margins. Provides a simplified method to obtain a secure region of operation, which can be a useful in an operations environment. The above work demonstrates the positive impact that utilizing the capability curve of wind parks has on the voltage performance of a power system. The additional benefit is especially amplified for those wind parks that are in close proximity to load centers.

\section{REFERENCES}

[1] Abed,M "WSCC Voltage Stability Criteria, Under-Voltage, Load Shedding Strategy, and Reactive Power Reserve Monitoring Methodology," in Proc. IEEE Power Engineering Society Summer Meeting, Vol. 1, Edmonton, AB, Canada, pp. 191-197. 17. (2009).

[2] Ajjarapu, V, Computational Techniques for Voltage Stability Assessment and Control, New York: Springer Science, 2006, pp. 1-3. 16. (2006).

[3] American Wind Energy Association (AWEA), "Legislative Affairs", Retrieved on $17^{\text {th }}$ July, 2008, from Available: http://www.awea.org/legislative/ 8.

[4] American Wind Energy Association: 2009: Another Record Year for Wind Energy Installations. 4.

[5] Berry, M. Jaccard, "The Renewable Portfolio Standard: Design Considerations and an Implementation Survey”, Energy Policy, Vol. 29, No. 4, pp. 263-277, 6. (2001) 
[6] Bhattacharya, J, "Reactive Power as an Ancillary Service," Power Engineering Review, IEEE, Vol. 21, No.5, Pp. 64-64, May 2001 21. (2001).

[7] Bird,L Bolinger, M Gagliano, R. Wiser, M. Brown, B. Parsons, "Policies and Market Factors Driving Wind Power Development In The United States", Energy Policy, Vol. 33, No. 11, pp. 1397-1407. (2005).

[8] Doherty,R, "Establishing The Role That Wind Generation May Have In Future Generation Portfolios," IEEE Transactions on Power Systems, vol. 21, no. 3, Pp. 1415-1422, August 2006. 3. (2006)

[9] Federal Energy Regulatory Commission (FERC), Order No. 661 on Interconnection for Wind Farms, June 2, 2005.

[10] Federal Energy Regulatory Commission (FERC), (2005). Order No. 661A (Order on Rehearing) on interconnection for wind farms.

[11] Feng,D Chowdhury, H Crow, L, "Improving Voltage Stability By Reactive Power Reserve Management," IEEE Trans. on Power Systems, Vol. 20, No.1, pp. 338-345, February 2005. 18. (2005).

[12] G. Tapia, A. Tapia, J.X. Ostolaza, "Proportional-Integral Regulator-Based Approach to Wind Farm Reactive Power Management for Secondary Voltage Control," IEEE Trans. on Energy Conversion, Vol. 22, No. 2, pp. 88-498, June 2007. 24.

[13] Hansen, L Hansen,H, "Wind Turbine Concept Market Penetration over 10 Years", Wind Energy, Vol. 10, No.1, Pp.81-97. (2004).

[14] Hughes, O. Anaya-Lara, N. Jenkins, Strbac, G. "A power system stabilizer for DFIG-based wind generation,” IEEE Trans. on Power Systems, Vol. 21, No. 2, Pp. 763-772, May 2006. 23. (2006)

[15] Kundur,P. Power System Stability and Control. New York: McGraw-Hill, 1994, pp. 27-33, pp. 209-211. 14. (2011).

[16] Lund, P. Sorensen, J. Eek, "Reactive Power Capability of a Wind Turbine with Doubly Fed Induction Generator", Wind Engineering, No. 10, pp. 379-394. (2007).

[17] Dommel,W Tinney,F (2008). "Optimal Power Flow", IEEE Transactions on Power Apparatus and Systems.

[18] Miller,T, Reactive power control in electric systems, Wiley, New York (1982), pp. 129131. (2010).

[19] Ming Ni, J.D. McCalley, V. Vittal, T. Tayyib, "Online risk-based security assessment," Power Systems, IEEE Transactions on, Vol.18, No.1, pp. 258-265, Feb 2003 13. (2013).

[20] Parsons B. "Grid Impacts of Wind Power: A Summary of Recent Studies in the United States", Wind Energy, Vol. 7, No., Pp. 87-108. (2004).

[21] Renewable Energy Policy Network for the $21^{\text {st }}$ Century, Global Status Report: 2009.

[22] S.Muller, M.Deicke and Rik W. De Doncker, "Doubly Fed Induction Generator Systems for Wind Turbines," IEEE Industry Applications Magazine, pp. 26-33. (2002).

[23] Tapia,A Tapia,G Ostolaza, A. "Reactive Power Control of Wind Farms For Voltage Control Applications", Renewable Energy, Vol. 29, No. 3, Pp. 377-392, March 2004. (2012).

[24] Taylor,W, Power System Voltage Stability. New York: McGraw-Hill, 1994, Pp. 6- 13. 15. (2004).

[25] Van,T, C "Voltage instability: Phenomenon, countermeasures and analysis methods," Proceedings of the IEEE, Vol. 88, No. 2, pp. 208-227, Feb 2000.

[26] Website: Institute of Energy Technology-Aalborg University: www.iet.aau.dk/education 10.

[27] Zavadil,R Miller, N Ellis, A and Muljadi,E, "Making connections," IEEE Power \& Energy Magazine, Pp. 26-37, November/December 2005. 